\title{
Leer y conversar, el discurrir de la tertulia literaria en una clase de sexto
}

\author{
Ma Dolores Molina Galvañ \\ Universidad de Valencia \\ mail: m.dolores.molinaduv.es \\ ORCID: https://orcid.org/0000-0003-1168-405X
}

\section{RESUMEN}

Este artículo compone la historia curricular de una experiencia de acompañamiento en un aula de Educación Primaria. La historia se centra en el discurrir de la tertulia literaria, que es la forma pedagógica con que esta maestra abre un tiempo para leer y conversar juntos en clase. Una historia que va entrelazándose con las historias que la anteceden y, a su vez, con nuevas historias que emergen a partir de ella. El artículo estructura una temporalidad que recorre longitudinalmente la trama narrativa de esta experiencia educativa mostrando en su recorrido, y de forma narrativa, los cambios, las invenciones y los desbordamientos que se van aconteciendo; con todo esto nos acercamos a un modo de vivir el currículum como un plan que se va componiendo y co-componiendo en el propio proceso de enseñar y aprender.

Palabras Clave: Indagación narrativa, tertulia literaria, creación curricular.

\section{Reading and talking, the course of the literary gathering in a sixth grade class}

\section{ABSTRACT}

This paper presents the curricular story of an experience of being alongside a Primary Education classroom. The story focuses on the course of the literary circle, which is the pedagogical method with which this teacher facilitates a time to read and talk together in class. A story that is intertwined with the stories that precede it and, at the same time, with new stories that emerge from it. The article structures a temporality that runs longitudinally through the narrative plot of this educational experience showing in its journey, and in a narrative way, the changes, inventions and overflows that take place during its course. This implies approaching the curriculum as a plan that is being composed and co-composed in the very process of teaching and learning.

Keywords: Narrative inquiry, literary circle, curriculum making.

ISSN: 0210-2773

DOI: https://doi.org/10.17811/rifie.50.3.2021.697-704 


\section{Introducción o la presentación de la inquietud investigativa.}

En octubre de 2018 vuelvo a la escuela, retomo mi rutina investigadora de acompañar el quehacer cotidiano de una maestra en su aula ${ }^{1}$. En el camino a la escuela me encuentro con criaturas que, solas o acompañadas, se dirigen hacia ella. Camino con el trazado de sus carreras, sus juegos y sus risas esperando que emerja la silueta del edificio entre los árboles que la rodean. Y llega un punto que aparece sin más. La escuela, pienso, no es un lugar cualquiera. Entrar a la escuela no es entrar a un lugar cualquiera, y las cosas que se hacen en ella no son cualquier cosa (Larrosa, 2019). ¿Cómo son esas cosas que se hacen y suceden en la escuela? ¿Cómo llegan a acontecer? ¿Qué las hace posibles? ¿Y viables, y sensibles, y fructíferas, y sensatas, y necesarias? Son preguntas con las voy a la escuela. Que persisten de visita en visita tratando de tensionar mi mirada para que no se empañe.

Preguntas que me acompañan mientras aprendo un lenguaje y una lengua que no cosifique la vida y el mundo que se abre en la escuela. Tampoco las formas con las que lo hace.

No es el primer curso que acompaño a esta maestra, Inma. De hecho, es el quinto. Lo que me lleva a su aula cada curso, como si fuese la primera vez, es aprender a hacer eso que hace con un saber próximo al saber virtuoso del artesano (Larrosa, 2018). Crear entornos fructíferos, culturales y habitables para el aprendizaje (Garcés, 2020). Un trazo de esa sabiduría que alienta su hacer es el cuidado que pone en facilitar el despliegue de la vida de las niñas y los niños. Otro trazo de su hacer es generar interés por el mundo, los asuntos del mundo, despertando el deseo de saber y de hacer crecer ese saber, sin sobrepasar o desestimar las inquietudes y las necesidades con las que vienen las criaturas. Y en estos trazos se hacen presentes dos disposiciones fundamentales en la forma de vivir su oficio. La primera es no dejarse atrapar en las prescripciones expertas que atribuyen a la infancia, en la escuela, una función (lo que tienen que hacer), una explicación (lo que les pasa) y un destino (lo que son o no son capaces de hacer) (Punta, 2019, Simons y Masschelein, 2014). La otra disposición es concebir el saber y el conocimiento como una experiencia que involucra todo nuestro ser. La cultura no aumenta lo que tenemos sino lo que somos (Bellamy, 2018; Petit, 2015; Recalcati, 2016). Para esta maestra, la enseñanza y el aprendizaje son experiencias relacionales que requieren cuidado y atención para generar vínculos, para crear un entre que permita a las criaturas relacionarse con el saber. Y que les ayude a componer el sentido educativo de ese estar juntos en el aula. Buscando que el saber les diga algo a las criaturas, que las involucre sin aportar tensiones gratuitas, competiciones, retos, sobrecargas (Coscollà, 2016). ¿Cómo se relaciona esta maestra con el entramado curricular para generar, con las criaturas, estas experiencias relacionales con el saber?

Vive con pasión el inicio de curso. Es un tiempo para darse a pensar e imaginar el devenir de lo posible. De concretar lo que desea proponer y lo que desea que abran sus propuestas. Sin embargo, su forma de hacer y estar no se orienta desde la proyección (sobre los otros y lo otro), sino desde la afectación. Esto es, desde un dejarse afectar por la realidad que tiene delante, en sus manos. Acepta que lo que le viene dado y lo que le llega, no siempre lo elige y, desde luego, no lo puede borrar. Está ahí. Es lo que tiene y es desde dónde se pone a caminar. Y advierte que esta disposición en el hacer no lleva consigo la renuncia. El hacer desde la afectación no es un hacer para la adaptación. Es otra cosa. La posibilidad de interpelarse en los automatismos y la posibilidad de (re)pensar desde sí las situaciones que se le presentan (Punta, 2013). ¿Cómo se relaciona con las tensiones que existen entre la obligación y el deseo? ¿Entre lo que viene dado y lo que es necesario? ¿Cómo vive las disonancias de las diferentes sensibilidades pedagógicas? ¿Cuáles son sus irrenunciables?

Acompañando una vez por semana a la maestra en su quehacer cotidiano, voy apreciando el espacio del aula como un lugar que mueve la vida y que acoge la vida en movimiento. Me llega frecuentemente una imagen del aula cercana a esas cabañas de la infancia. Esos lugares acogedores, propios y abiertos a la vez, que nos cobijan en un espacio que es fuera del espacio y en un tiempo que es fuera del tiempo. Un enclave protector donde anidar y explorar y crecer (Díez, 2015; Van Manen, 2004). Un refugio donde nuestras existencias y extrañezas tienen cobijo (Garcés, 2020; Meirieu, 2007). Una guarida que nos separa, suspendiéndolas, de las exigencias y expectativas de un tiempo productivo y de un tiempo de trabajo para ofrecernos tiempo libre para el estudio (Simons y Masschelein, 2014).

Elijo esta metáfora de la cabaña, porque me conecta también con la experiencia que narro en este texto. Esta imagen es una invitación a reconocer el aula como un lugar que toca nuestros cimientos espaciales de la existencia. Metáfora de un espacio que da amparo e intimidad y de un espacio también, que conjuga nuestro mundo interior con el paisaje de un mundo que nos antecede y acoge en un lecho cultural. Una conjugación posible entre lo íntimo, lo inmenso y lo lejano (Petit, 2015).

\section{El paisaje o el entramado relacional en el que se compone esta historia.}

La escuela, y la propia aula, son paisajes en movimiento. Paisajes alterables y cambiantes que se componen y recomponen desde múltiples historias que se cruzan y se entrecruzan (Clandinin, 2015). Historias personales, institucionales, sociales, políticas y culturales. El paisaje se conforma en un entramado relacional en el que somos y vamos siendo. Un lugar de ensamblajes con permanentes ajustes y desajustes. El paisaje nos acoge y nos resiste y nos trasciende. Es en la relación entre historias y tramas del paisaje en donde se crean y recrean las historias curriculares (Olson, 2000; Parker et al.,2011).

Cada inicio de curso Inma dedica un tiempo a componer el paisaje en el que está inmersa. Lo hace en forma de mapa mental. En el centro del papel, el curso que corresponde (2018-2019), a su alrededor la clase, ella, el cole. Colores, flechas, palabras, dibujos le sirven para componer ese entramado relacional entre las personas, las cosas, las preguntas, los acuerdos, las previsiones, los deseos, los tanteos, los cambios, las intenciones, los talleres, los proyectos, los compromisos. El mapa mental deviene en una narración cuidadosa y exquisita del paisaje que le permite entender algo más de él. Sobre todo, le permite verse en él. Detenerse en los detalles, conocer las condiciones, intuir las tensiones, vislumbrar las oportunidades, buscar el sostén, esperar lo posible, propiciar lo deseable. Este mapa, dice, le sirve para aclararse, para situarse, para tomar distancia y pensarse en el discurrir del curso y pensar el discurrir del propio curso. Le sirve para tantear formas de habitar el currículum y para ver resquicios y deambularlo. Esto es, para encarnarlo y para recrearlo.

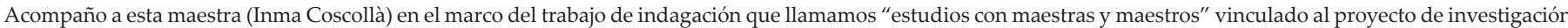

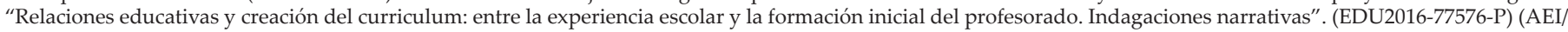
FEDER, UE). 
Este curso es tutora de $6^{\circ} \mathrm{B}$. Se reconoce en la dificultad de relacionarse con la sensibilidad pedagógica y el estilo docente que se vive en el equipo del tercer ciclo. La decisión de trabajar con libros de textos, por ejemplo, la incomoda. Es una tensión presente. Está ahí. No puede negarla ni sobrepasarla. Le preocupa cómo cuidar la relación sin ceder sentido de lo que para ella es irrenunciable. El mapa mental, me dice, le ayuda a buscar resquicios, a pensar maneras posibles de caminar juntas sin necesidad de caminar del mismo modo. Sabe que este curso no puede hacer proyectos. La cuestión es cómo traer y hacer lugar, en su aula, a aquello que los proyectos de trabajo tienen de potentes o lo que ella ha vivido como potente al trabajar por proyectos. En este desplegar narrativamente su mapa mental, consigue visualizar formas pedagógicas con las que vivificar sus inquietudes curriculares: las cajas de vida, los trabajos voluntarios, la tertulia literaria, las preguntas viajeras, las salidas, los planes de trabajo, las exposiciones, el libro de vida. La planificación trimestral de Inma se asienta en un ir componiendo el puzzle curricular con estas piezas. Es con ellas, me explica, como puede hacer que la experiencia de enseñar y de aprender convoque situaciones que se muevan hacia la interrogación y la búsqueda, hacia el análisis y la reflexión. Situaciones en las que cada cual se sienta vinculado a partir de las posibilidades, las necesidades y las emociones que se le despiertan. La relación con el saber fructifica, insiste, si trae intensidad y sensibilidad. Si contiene trayectoria vital para acoger la vibración del cuerpo en su relación con lo conocido y con lo que está por conocer (Molina, 2018).

Tras varios años como jefa de estudios, este curso ya no forma parte del equipo directivo. Además, es su penúltimo curso antes de jubilarse. Hay que aprender a soltar y a vivir otro futuro próximo. Ciertamente hay mucho movimiento en la escuela y mucho movimiento interior, también. El mapa mental le ayuda a verse en relación con todo ello, a esponjar el paisaje, a reconocer su permeabilidad para imaginar la vida que quiere hacer posible. Porque no se trata sólo de resolver su incomodidad haciendo lo que desea en su aula con sus criaturas. Quiere pensar otras cuestiones más amplias. Cómo va a estar y de qué modo va a hacerse presente en el equipo de nivel y de ciclo y en la comisión de centro de la que forma parte. Cómo puede estar ahí, en relación, desde la cordialidad, la disponibilidad, la prudencia sin renunciar a su estilo y sin juzgar otros. Necesita decidir dónde es mejor que esté en segundo plano para no violentar o dónde puede tener más lugar para hacer crecer otras cosas. Desea sostener y vivir con alegría las actividades comunes de la escuela: los talleres del tercer ciclo, las clases hermanadas, el proyecto de centro sobre el arte, los carnavales, la semana cultural, el viaje de fin de curso. Para Inma es fundamental esta mirada más amplia del paisaje de la escuela. El respeto, la confianza, el cuidado de las relaciones son importantes para la existencia de cierta armonía. Es desde aquí como se hace vivible la divergencia y el disenso sin caer en la indiferencia o el conflicto sostenido. En esta escuela esto se cuida mucho. No se persigue ni se exige la concordancia, pero sí se buscan confluencias que aviven la transversalidad del encuentro (Molina, 2018).

Inma cuenta conmigo este curso, me dice. Acompañarla es ya una práctica habitual para mí, para ella y para las criaturas. Se vive con cierta naturalidad mi presencia intermitente en el aula con mi libreta para tomar notas, con mis gestos interrogativos ante los cambios que percibo en el aula con cada visita, con mi deambular tranquilo entre los grupos cuando están trabajando. Voy a la escuela, les explicamos a las criaturas y a las familias, para aprender de la escuela y para llevar algo de eso que aprendo a mis clases en la universidad.
Compartir este sentido formativo de la investigación ha ido tejiendo, entre nosotras, un hilo vivo y vital de complicidad. Por eso, surgen las preguntas. ¿Dónde podríamos situar este año mi acompañamiento? ¿Cuál de esas piezas curriculares podría seguir a lo largo del curso? ¿De qué tiempo dispongo para acudir a la escuela? Entre lo que se desea y lo que se puede, siempre opera el encaje de horarios. Sé que la decisión de acompañar el tiempo de la tertulia literaria fue producto de ese encaje.

\section{La tertulia literaria o la historia de las dudas e incomodidades iniciales.}

La tertulia comenzó a mediados de noviembre. Ello me permitió conseguir con calma el libro de lectura: la adaptación escolar de El jardín secreto de Frances Hodgson Burnett. No esperaba que la lectura elegida fuese una adaptación. Me sorprendí. Cuando encuentro ediciones adaptadas de los grandes relatos, percibo el límite de una visión recortada del trayecto a la que cualquier historia es susceptible de llevarnos. Y a su vez, una esperanza recortada sobre nuestros propios trayectos para entrar en ella. Diría que esta primera cita con la tertulia puso algo en crisis, me trajo las dudas. Comenté algo de esto a Inma. Sólo me dijo que la elección del libro era herencia de cursos anteriores y la conversación fue yendo hacia otros lugares. Había una novedad. Laura, que ya ha pasado al instituto, le ha pedido a Inma si puede repetir en la tertulia. Recuerda con entusiasmo la experiencia vivida el curso anterior y desea revivirla de nuevo. La noticia rebaja mi incomodidad.

La tarde del primer miércoles de noviembre comienza la tertulia. Acudo sin apenas leer la contraportada, como sugirió Inma. Las semanas anteriores había entrado en el aula para entrar en relación con las criaturas. Conocía a muchas de ellas, cursaban tercero y cuarto cuando empecé a acompañar a Inma en su aula. Volver a coincidir en su último año en la escuela era, para mí, emocionante. La tertulia literaria comienza tras realizar el plan de trabajo de lengua valenciana. Los planes de trabajo se organizan como tiempo de trabajo individual. Un tiempo de concentración, de calma, de silencio. Para llevarnos hasta ahí, Inma pone música instrumental de fondo, casi siempre algo de jazz o de blues. Si alguien acaba antes, puede ayudar a su compañera o compañero, dibujar, leer o hacer alguna otra cosa. Son casi las 16:00 h y ya todo el mundo está haciendo otra cosa. Inma nos invita a recoger el material y respirar un minuto. Hay nervios y expectación en clase porque se abre este tiempo nuevo de la tertulia literaria en su rutina escolar. Mientras vamos saliendo de la respiración, los responsables de este mes comienzan a repartir los libros que están en la estantería del primer armario junto a la puerta. Inma de pie, de espaldas a la pizarra y entre los dos extremos de la U, comienza la lectura del primer capítulo en voz alta. Tras un par de párrafos ofrece, a una de las criaturas, continuar con la lectura. Luego a otra, y a otra, y a otra hasta llegar al final. Cada capítulo tiene entre siete y once páginas. Y entre ellas siempre hay alguna ilustración. Preciosas, por cierto.

Tras la lectura se inicia la conversación. En este tiempo se comparten dudas, opiniones, preguntas y reflexiones. Distintos pareceres sobre aquello que nos ha llegado de la lectura, lo que nos ha tocado de la historia y lo que nos ha movido la ilustración. La conversación comienza con muchas manos levantadas, y queda poco tiempo de clase. Algo menos de quince minutos. En realidad, sólo cinco criaturas han podido tomar la palabra. Nos vamos con una sensación extraña. Sentí algo de interrupción y precipitación y cierre. La segunda cita con la tertulia literaria me desanima un poco. De camino al metro lo hablo con Inma. ¿No será que el tiempo de la tertulia necesita ser más largo? ¿No 
es mucho esperar leer y conversar en el tiempo del que se dispone? ¿La idea es conversar a partir de la lectura o sólo tantear algo de cómo la lectura va llegando al grupo a modo de sondeo? Compartimos impresiones e inquietudes y la cosa se nos queda dentro, rumiando.

De vuelta en casa, retomo la lectura del capítulo sin avanzar al siguiente. Quiero respetar el ritmo de lectura y quiero avanzar en la historia al ritmo en que lo hacen las criaturas. Ir de nuevo al capítulo me permite disfrutar los detalles de la ilustración. Darme cuenta de algo que no había percibido durante la lectura ni en ese airear inicial las páginas del libro. En el capítulo hay pies de página que aclaran el significado de ciertas palabras: institutriz, despótica, aya, balbucir, desgarrador, ensimismamiento, sigilosa, comensales, entre otras. El libro acaba con una guía de lectura y actividades. Pienso, no, seguro que no lo hubiese elegido. Por un momento dudé si me refería al libro o a la decisión de acompañar la tertulia. Tomé un respiro y confié en Inma.

\section{Leer y conversar o la historia de cómo se reinicia la tertulia.}

La semana siguiente la tertulia se abre con la lectura del resumen que hace Inma. Sentados en U escuchamos con atención sus palabras. Narra cómo comenzamos la tertulia, cómo fue la lectura, de qué se habló en el turno de palabras. Recuperó también, algo de nuestra valoración posterior. Un texto breve que recorría con calma y cuidado la sesión anterior y que nos removió por dentro. Sucedió algo en el ambiente, aunque no tenía palabras para nombrarlo. Sí sé que se tambalearon mis dudas. Hacer el resumen, explica Inma, le había servido para revivir la sesión anterior y pensar despacio en ella. Se le había ocurrido una cosa y quería saber nuestra opinión. ¿Nos parecía posible, y aceptable, partir el grupo en dos? Un grupo se quedaría conmigo y otro con Inma. Un grupo haría la tertulia en el aula y el otro en la biblioteca. Ello nos ayudaría a leer con calma para crecer en la lectura. Nos daría más tiempo para conversar y crecer en la escucha, la atención y la expresión de nuestras ideas. La idea que traía Inma nos revolvió a todos. Nos atravesó y nos sorprendió. Se hizo un breve silencio que Inma sostenía con una sonrisa, sabía que había tocado algo importante. Sentí cierto pavor que se convirtió en vértigo cuando las criaturas aceptaron sin fisuras la propuesta. Después, iniciamos la lectura del segundo capítulo del libro. La descripción del ajetreado trayecto de Mary desde la casa del señor Crawford en la India a la mansión de su tío en Misselthwaite (Inglaterra), ponía palabras e imágenes al vértigo que me abrió el giro que proponía Inma para la tertulia. Respiré y confié en las criaturas de 6으.

De camino al metro se me atropellan las preguntas, aunque no me salen las palabras. Inma parece contenta y confiada, aunque afirma no tener ni idea de cómo puede acontecer la tertulia. Necesitamos, me dice, pensar con calma los tres ejes de la tertulia. El sentido educativo de leer, de conversar y de compartir (con los resúmenes) la vida que va tomando la tertulia. Sólo me sale escucharla, el trayecto hasta el metro es corto y la tarea que me pone, larga. Tenemos que dejar, para el miércoles siguiente, la decisión sobre quién va a la biblioteca y quién se queda en el aula.

Durante la semana voy rumiando esto del sentido educativo en los ejes que estructuran la tertulia. Leer, conversar y relatar. Pienso en aquello que me gustaría conversar con Inma. En aquello que quisiera hacer crecer junto a las criaturas. Y lo voy anotando en mi diario de campo. Leer conlleva ensimismamiento. Nos acerca al silencio. Nos da cobijo. Nos aporta quietud y lentitud. Restituye, en cierto modo, ese mundo interior siempre en un movimiento resquebrajadizo. La lectura declina en una forma de escucha, pues los libros nos hablan, nos acercan y nos abren las palabras del mundo. La lectura proyecta belleza sobre lo cotidiano y nos da trasfondo poético a la vida. Cuando se nos meten dentro, hay lecturas que no dejan de crecer, que nos acompañan en el devenir de nuestra vida. "Los lectores escriben su propia geografía e historia entre las líneas leídas [...] Leer sirve para encontrar fuera de sí palabras a la altura de la propia experiencia" (Petit, 2015, 56-57). Conversar implica levantar la vista del libro para adentrarse en el mundo al que nos ha llevado la lectura. Aprender a habitar ese espacio, y hacerlo en compañía de otros. La conversación aviva nuestro pensamiento y activa nuestra inventiva. Conversar nos acerca al otro para llevarnos más lejos. En el conversar vamos construyendo nuestra realidad con los otros. $Y$ las palabras nos duelen o nos reconfortan porque no se trata sólo de una forma de hablar sino de un aprender a vivir juntos en el presente, en cada relación en la que se pone el cuerpo y nos aventuramos a tejer una trama. Relatar nos ayuda a dar sentido al flujo de la experiencia. La ordena y le da envoltura narrativa, esto es, le pone palabra, la nombra. Es en la trama narrativa donde la experiencia adquiere orden y forma, aunque sea provisional. En la trama narrativa, la experiencia se presenta y representa, se hace reconocible para otras y otros. Relatar es contar(nos) historias sobre lo que hemos vivido, lo que ha acontecido y nos ha pasado con ello. Las historias que nos contamos nos hacen volver a la experiencia. Revivirla. Y en este revivirla, encontrar nuevos detalles, matices, cadencias, signos, señales que nos dan más conciencia de ella y nos permiten interrogar y repensar el sentido de lo que hacemos. Compartirla nos permite abrir nuevas relaciones y versiones de ella. Y me subrayo en el diario, ¿no sucedió algo de esto cuando Inma leyó su resumen?

El miércoles siguiente llego apurada de tiempo a la escuela. Encuentro a Inma ya en las escaleras. Subimos a clase rápido mientras trato de balbucear algo de lo que venía pensado de camino al cole. Pero hay cosas pendientes que son urgentes. Decidir quien se queda en el aula y quien va a la biblioteca. Decido quedarme en el aula, me parece más prudente. Hoy, además, es el primer día de Laura. Inma propone que se quede conmigo y acepto. ¿Cómo leemos: en silencio, en voz alta, una lectura dramatizada? La pregunta se queda en el aire, llegamos al umbral de la puerta del aula. Ya no cabe. Haremos lo que podamos, pienso para conformarme.

\section{Los resúmenes o la historia del discurrir de la tertulia y qué discurrimos en ella}

Verme sola con el grupo en la clase me hizo sentir cierta impostura. Hacerme responsable de un grupo en la tertulia, igual me quedaba un poco grande. Sin embargo, allí estábamos. Algo había que hacer. Nos ponemos en círculo y les propongo hacer una lectura en voz alta. Una lectura dramatizada con reparto de los personajes. Les gusta, y enseguida surge un primer problema. Hay más lectores que personajes. Sin pensarlo mucho, planteo que cada personaje tenga dos lectores. Por suerte, pensé, no todos querían leer. Nos quedó la sensación de que no fue mal del todo. Era divertido esto de la dramatización, aunque había ocasiones que no se tenía claro a quién le tocaba leer.

Me llevaba de esa tarde tres cuestiones que quería pensar y cuidar. Una, situar la relación con las criaturas. Ya no estaba sólo en el aula para aprender con Inma a ser maestra, que era el lugar desde el que nos habíamos relacionado todo el tiempo. Los nervios, las risitas, los despistes, el atropello al hablar tenían mucho que ver con una cierta descolocación ante una relación que ya no es como era, pero todavía no se sabe bien qué es. Otra cosa para pensar y cuidar, era la escucha y el acercarme a las criaturas. Me 
descubrí con mucha dificultad para seguir lo que decían, para encontrar sentido a lo que decían, para reconocer el lugar desde dónde decían. La infancia se me aparecía como un misterio insondable. Se me hacía difícil recoger hilos de los que tirar y hacer preguntas que nos ayudasen a pensar. La tercera cuestión era aprender a sostener sus tanteos relacionales. Inma los llama "los pulsillos". Están ahí en medio, moviéndose mientras se va aclarando y acomodando la relación.

De camino al metro comento todo esto con Inma. Ella escucha sin poner prisa y cuando nos separamos, me recuerda que tengo que hacer el resumen para la semana que viene. ¿Podría ser el resumen un lugar desde el que ir tirando de estos hilos para conocernos y reconocernos mejor? Concretamos que los resúmenes habían de recoger tres preguntas. Cómo había ido la lectura. Qué trama se ponía de relieve en cada capítulo. Cómo se abría y discurría la conversación. Concretar estas cuestiones me ayudaba, aunque la dificultad la sentía en otro lugar. La dificultad de recoger con fidelidad aquello que se decía en la conversación. No lo vivía como una cuestión de reproducir o no las palabras exactas de las criaturas, se trataba más bien de ser fiel a lo que sus palabras decían y al lugar desde dónde lo decían. Me asustaba que el resumen ensombreciese a las criaturas o que las violentara.

La semana siguiente la tertulia comienza con la lectura de los resúmenes. El de Inma y el mío. Siempre es así, se leen los resúmenes y luego se separan los grupos para avanzar en la tertulia. Aunque con estilos diferentes, los textos se tocaban en su forma. Detallaban lo que se había sucedido y cómo fue vivido. Recuperaban lo que se había dicho y quien lo había dicho, mostrando un conversar cuyo trenzado no siempre se sentía y vivía con claridad cuando se estaba sucediendo. De algún modo, los resúmenes eran el reposo, y el poso, de una vivencia intensa y fugaz al mismo tiempo.

Los resúmenes van mostrando cómo nos vamos aproximando a la lectura y cómo estas aproximaciones van cambiando hasta que se asienta un modo de hacer. En los resúmenes de Inma se ve cómo se pasa de una lectura personal en silencio a una lectura colectiva en voz alta. Se iban dando cuenta de que tenían ritmos diferentes de lectura y que todo el mundo quería terminar de leer el capítulo antes de comenzar la conversación. En mis resúmenes aparece que hacer la lectura a través de los personajes, nos llevó a decidir si tener un ratito de lectura todos en cada capítulo o ajustar los lectores a los personajes que aparecían en cada capítulo y cambiar cada semana. Este proceso que inicia cada una con su grupo, vuelve a ponerse de relieve en febrero cuando rotamos los grupos. Y hay cosas que cambian. En mi grupo no seguimos con la lectura dramatizada, las criaturas preferían leer como lo venían haciendo con Inma, un ratito cada uno, sin obligación de tener que leer todos. Así que, al comenzar, siempre estaba la pregunta "¿quién quiere leer?".

Los resúmenes iban recogiendo las tramas centrales de cada capítulo y la conversación a la que nos iban llevando. Cuando Inma los leía en voz alta, nos hacíamos conscientes de la coincidencia o la diferencia de lugares de conversación a los que nos había llevado a cada grupo. Sin embargo, aunque se abriesen en relación a distintos capítulos y de formas distintas, se apreciaban ciertas preocupaciones comunes: la relación con los hermanos, la preocupación sobre cómo somos vistos por los demás, el miedo a la soledad pero también la necesidad de tener tiempo de estar solos, los secretos, la atracción y el miedo que provoca el misterio, las relaciones con los adultos, los deseos y los sueños, las necesidades materiales y afectivas y sociales, el bienestar que provoca hacer las cosas que nos gustan, la fragilidad que nos trae la enfermedad o la tristeza, la alegría de la amistad y también la dificultad de hacer amigos, los prejuicios y las palabras que nos hacen daño, la belleza de los atardeceres en nuestros lugares preferidos, los límites que necesitamos y lo que hace interesante o no una historia. El recorrido de estos hilos, su profundidad y claridad, y su sentido más vital y encarnado, no surgía sólo desde un dejarse tocar por la lectura de cada capítulo. Se generaba, sobre todo, por nuestra sensibilidad para percibir eso que les tocaba y ayudarlos a conectar con su propia historia. En mí sentí mucho esa dificultad. No logré hacer bien ese movimiento que descentra lo cognitivo para hacer lugar a lo experiencial. Aprendí mucho prestando atención a esta dificultad, pero se mantuvo ahí de una u otra manera todo el tiempo.

Los resúmenes van revelando el tacto y el cuidado puesto en la relación y en la redacción. Era importante cuidar esa relación naciente entre lo vivo y lo viviente. En su composición se percibe la atención que se pone en las palabras de las criaturas y, también, en procurar su presencia. Ese ir tejiendo el texto a partir de lo que se dice y quien lo dice, hizo de los resúmenes un lugar de encuentro afectivo muy importante. La lectura de los resúmenes se convirtió rápidamente en el momento más intenso y esperado de la tertulia. Inma lee un resumen y sucede un aplauso. Lee el otro resumen y sucede otro aplauso. Estos textos son la historia de la tertulia $\mathrm{y}$, sobre todo, su historia en la tertulia. El poso que va dejando cada resumen muestra ese movimiento sensible entre la fidelidad y la transcendencia. Una cierta epistemología del tránsito (Anzaldúa, 2016) que hace posible tocar la materialidad de la vida, nombrándola, y que hace posible arroparla dándole un lecho cultural. En la composición de los resúmenes se me abre la oportunidad del vínculo, del consentimiento, de la confianza, del permiso de las criaturas, lo que ayuda también a incorporar los tanteos relacionales y atravesarlos juntos. La relación madura de semana en semana, se nota, y las criaturas se dejan decir con esta mirada reposada y elaborada que nos devuelven los resúmenes. En febrero, cuando hacemos el cambio de grupo, cuando la tertulia ya tiene un recorrido y cuando los resúmenes se han convertido en los textos que hablan de nuestra historia en la tertulia, algunas criaturas se deciden a hacer ellas mismas el resumen. Así ocurre en el grupo de Inma. En mi grupo no se deciden a dar el paso, aunque una o varias criaturas se encargan de tomar notas de la conversación en mi libreta, y hago el resumen a partir de lo que han recogido en esas notas. Los resúmenes aumentan, se pasan de manos e incorporan ilustraciones, porque las notas de Oscar son sus dibujos, y su dibujo es una parte más de nuestro resumen.

En el conjunto de los resúmenes queda registrado el sentido educativo de la tertulia. Abrir un tiempo de trabajo en relación en el que aprendemos a escuchar, a pensar y a hablar. Y, aunque no siempre nos sale bien, sí está siempre el deseo de mejorar.

\section{El desbordamiento o las historias que nacen por fuera de la tertulia.}

Cerca y alrededor de la tertulia comenzaron a sucederse otras cosas que desbordaban tanto las previsiones docentes de Inma como mis previsiones indagativas. En la escuela, Inma y las criaturas hacían movimientos en el horario que me permitían involucrarme en algún momento del recorrido de otras piezas curriculares. Y a su vez, proponían acciones en las que se involucraban más en el discurrir de mis clases universitarias. Todo sucedía, como dice Inma, de manera natural. Sin forzamientos, sin imposturas, sin tensiones.

En noviembre, Yolanda y Tessa, me hablaron de su idea para un trabajo voluntario. Sólo lo sabía Inma, y ahora yo. Querían interpretar la canción de Rozalén, La puerta violeta, en lenguaje de signos. Llevaban días preparándolo. Lo hacían en un tiempo 
que no era el tiempo de clase. Y se encontraban en lugares que no siempre eran la escuela. Conforme avanzaba su proyecto crecía más y más su entusiasmo y la seriedad en su trabajo. Sabían que el horario de los trabajos voluntarios coincidía con mi horario de clase en la facultad. No podría verlas. Tras las vacaciones navideñas, propusieron a Inma ocupar el tiempo del plan de trabajo del miércoles para presentar su trabajo voluntario. La maestra aceptó.

A finales de noviembre, invitamos a Inma a la facultad de magisterio para conversar con nuestros estudiantes. Otras maneras de vivir (y hacer) escuela, se titulaba su conferencia. Al terminar le regalamos tres libros. Uno para ella, otro para la clase de $6^{\circ} \mathrm{B}$ y otro para la biblioteca del cole. El libro para Inma era una de nuestras lecturas básicas en clase, Frankestein educador de Philippe Meirieu. Y el libro para la clase de $6^{\circ} \mathrm{B}$ era un relato de Khaled Hosseini, Súplica a la mar, con el que estábamos trabajando para pensar con él y a partir de él, cómo podríamos diseñar una propuesta didáctica. Esa misma tarde Inma les entregó el regalo a las criaturas y les comentó que era también nuestro libro de lectura. Inma lo leyó en voz alta, y luego lo fue pasando por los grupos para verlo con calma. La historia les atravesó y les conmovió profundamente. Escribieron textos breves expresando lo que la historia les hizo sentir y pensar. El miércoles siguiente, me dieron sus textos para que los compartiese con mis estudiantes. Junto a sus textos, una recomendación para ver un vídeo en youtube.

Las reuniones que Inma hace al final de cada trimestre con las familias para contarles el trabajo que han realizado, cómo se ha sucedido y que les ha pasado con ello, las organizó los miércoles por la tarde, tras la tertulia, para que pudiese vivir ese momento con ella y las familias. Mi presencia en el aula formaba parte de la vida de las criaturas en la escuela. Y para las familias, mi presencia era un elemento común dentro del paisaje escolar que acogían con cariño y confianza. Quizás por ello no les fue tan extraño verme allí, ni darme permiso para estar allí.

Alguna otra incursión hice en el aula más allá de la tertulia, cuando podía encajar horarios. Participando de algún plan de trabajo extraordinario y diferente que nació a partir de la propuesta que le hizo uno de los padres a Inma. O disfrutando de la presentación de alguna de las cajas de vida que hacían las criaturas y el juego o la canción que proponía. Porque este curso, los cumpleaños se celebraban así. Cada criatura preparaba, con ayuda o no de la familia, su caja de vida y decidía si quería compartir con la clase una canción o proponer un juego.

En mi clase y en la clase de Inma, compartimos otra lectura, Maternitats. Cuando las criaturas supieron que sus autores, Bru Rovira y Montserrat Castanys, nos visitaban en la facultad, pidieron venir para conversar el libro con ellos.

\section{A modo de cierre o un tanteo aproximado al currículum como proceso de creación}

La perspectiva narrativa concibe el currículum como un curso de vida (un camino que se recorre) y no como un plan de estudios (una meta que se cumple) (Olson, 2000; Parker et el., 2011). Decidí acompañar el desarrollo completo de una de las piezas curriculares que esta maestra pone en juego en su clase para prestar atención, precisamente, al discurrir de ese curso de vida. Al recorrido que la maestra ofrecía y a la experiencia educativa que se pudiera generar al recorrerlo. Componer las historias que pudieran surgir en este hiato, en este entre lo que se ofrece y lo que se sucede, ayudaría a visibilizar y a nombrar algunos hilos de sentido sobre la creación curricular. Sin embargo, en este proceder indagador se dio un giro inesperado, me encontré envuelta, involucrada, en el propio curso de vida de esa pieza curricular que pretendía estudiar. No fue algo previsto, ni esperado. Sólo pasó. Y quise incor- porarlo a mi proceder indagador como una invención más de la maestra en su modo de crear y recrear el currículum.

La experiencia vivida en este lugar entre, la mirada externa de quien observa un proceder y la mirada propia de quien sostiene ese proceder, me ha permitido complejizar la visión de las escenas y las situaciones vividas. Profundizar, por ejemplo, en ese saber de Inma para desplegar la vida de las niñas y los niños y, para generar su interés por los asuntos del mundo. Ese cuidado que pone para que todas las criaturas puedan sentir que están y que son en la vida común que se genera en el aula. Lo hace documentado la vida del curso en el libro de vida. Cada presentación de los trabajos voluntarios, cada caja de vida, cada texto propio que han escrito, cada exposición, cada salida, cada taller, cada celebración que implica al conjunto del centro, cada persona que les ha visitado en el aula. Entrelaza la vida del aula con la vida vivida de cada criatura en el aula. Eso mismo aprendí a hacer con ella en los resúmenes de la tertulia. Trazar y enlazar aquello que puede parecer disperso y desordenado. Aquello que, en la aplicación de cualquier plan curricular, puede quedar fuera de campo. También, ese saber estar cerca de la vida que vive cada criatura para ayudarles a poner palabra con las palabras y las historias que el mundo les ofrece. Saber relacionarse con su mundo-de-vida para abrir en ellas la posibilidad de vincularse y relacionarse con el saber y con el mundo, para sentirse concernidas con los asuntos del mundo (Simons y Masschelein, 2014). Los textos que las niñas y los niños de sexto escribieron a partir del libro Súplica a la mar, estaban impregnados de preguntas, de reflexiones, de sentimientos a los que no conseguí llegar con mis estudiantes. Sentí esa dificultad en mí y traté junto a Inma de aprender a vivir y a hacer vivir el saber como un proceso relacional más que como un proceso cognitivo. Como una relación que nos interpela como sujetos históricos y no tanto como sujetos epistémicos (Biesta, 2017).

Aprendí que una historia curricular, como la que relato aquí, se inscribe en el paisaje de las historias curriculares que la anteceden. Y que estas historias no siempre nos dan cobijo. Que tornar permeable un paisaje inhóspito requiere de historias nuevas que no nacen de la adaptación ni de la confrontación, sino de la afectación. De un dejarse afectar para encontrar resquicios de lo posible y anudarse a aquello posible que el paisaje ofrece.

Nuestros resúmenes de las tertulias fueron componiéndose como ejercicios narrativos que intensificaban el detalle poniendo voz, color, afecto e intensidad a la vida que se movía. Tener cuidado de los detalles nos sostenía, a las criaturas y a nosotras, en una atención flotante que mantenía abierta la vía de creación de sentido (López y Gabbarini, 2016). La historia de la tertulia termina al finalizar el libro. Sin embargo, sus efectos, esa llave que nos dio para indagar en nuestra geografía y nuestra historia no se cerró. Y la presencia de Laura decía mucho de ello. Los resúmenes, en tanto que ejercicios de indagación narrativa avivaron, también, un pensar pedagógico que dio sostén y recorrido a iniciativas que las criaturas iban tomando. Iniciativas que dieron otro giro al proceder investigador. Ahora era la escuela quien visitaba la universidad. Un giro en la indagación que fue abriéndose a otras experiencias y a otras historias, y que nos recordó que la educación es una creación delicada e incierta, pero potente (Contreras y Quiles-Fernández, 2017).

\section{Referencias Bibliográficas}

Anzaldúa, G. (2016). Borderlands-La frontera. Capitán Swing. Bellamy, F.X. (2018). Los desheredados. Por qué es urgente transmitir la cultura. Encuentro.

Biesta, G. (2017). El bello riesgo de educar. SM 
Clandinin, D.J. (2015). Stories to live by on the professional knowledge landscape. Waikato Journal of Education, Special $20^{\text {th }}$ Anniversary Collection 2015,183-194. DOI: 10.15663/wje. v5i0.403.

Contreras, J. y Quiles-Fernández, E. (2017). Vivir y profundizar experiencias de enseñanza desde una perspectiva narrativa. En Contreras, J. (ed.). Enseñar tejiendo relaciones (pp.19-34). Morata.

Coscollà, I. (2016). Pràctiques que ajuden a construir la relació educativa. Guix. Elements d'Acció Educactiva, 421, 55-59.

Díez, M.C. (2015). Los pendientes de la maestra. Graó.

Garcés, M. (2020). Escuela de aprendices. Galaxia Gutenberg.

Larrosa, J. (2018). Con P de Profesor. Noveduc.

Larrosa, J. (2019). Esperando no se sabe qué. Sobre el oficio de profesor. Candaya.

Lopez, A. y Gabbarini, P. (2016). Hacia una epistemología vulnerable. En Contreras, J. (comp.). Tensiones fructíferas: explorando el saber pedagógico en la formación del profesorado. Una mirada desde la experiencia. Octaedro.

Meirieu, P. (2007). Frankestein educador. Laertes.
Molina, M.D. (2018). Enseñar y aprender, la poética de la presencia en un aula de primaria: un estudio narrativo. Revista Educaçao UFSM, 43(2), 179-194. DOI: 10.5902/198464443211

Olson, M. (2000). Curriculum as a Multistoried Process. Canadian Journal of Education, 25(3), 169-187.

Parker, D.C, Pushor, D. y Kitchen, J. (2011). Narrative Inquiry, Curriculum Making, and Teacher Education. En Kitchen, J., Parker, D.C. y Pushor, D. (Eds.), Narrative Inquiries into Curriculum Making in Teacher Education (pp.3-18). Emerald Group Publishing Limited.

Petit, M. (2015). Leer el mundo. Experiencias actuales de transmisión cultural. Fondo de Cultura Económica.

Punta, T. (2013). Señales de vida. Bitácora de una escuela. Lugar Editorial.

Punta, T. (2019). Mundo escuela. Didácticas de equidad e inclusión. Paidós Educación.

Recalcati, M. (2016). La hora de clase. Por una erótica de la enseñanza. Anagrama.

Simons, M. y Masschelein, J. (2014). Defensa de la escuela. Una cuestión pública. Miño y Dávila.

Van Manen, M. (2004). El tono en la enseñanza. El lenguaje de la pedagogía. Paidós. 
